\title{
Decreased serum levels of brain-derived neurotrophic factor in schizophrenic patients with deficit syndrome
}

This article was published in the following Dove Press journal:

Neuropsychiatric Disease and Treatment

30 March 2015

Number of times this article has been viewed

\author{
Esra Soydaș Akyol' \\ Yakup Albayrak ${ }^{2}$ \\ Murat Beyazyüz ${ }^{3}$ \\ Nurkan Aksoy ${ }^{4}$ \\ Murat Kuloglu ${ }^{5}$ \\ Kenji Hashimoto ${ }^{6}$ \\ 'Deparment of Psychiatry, Yenimahalle \\ Education and Research Hospital, \\ Ankara, Turkey; ${ }^{2}$ Department \\ of Psychiatry, Faculty of Medicine, \\ Namık Kemal University, Tekirdag, \\ Turkey; ${ }^{3}$ Department of Psychiatry, \\ Biga State Hospital, Çanakkale, \\ Turkey; ${ }^{4}$ Department of Biochemistry, \\ Yenimahalle Education and Research \\ Hospital, Ankara, Turkey; ${ }^{5}$ Department \\ of Psychiatry, Faculty of Medicine, \\ Akdeniz University, Antalya, Turkey; \\ ${ }^{6}$ Division of Clinical Neuroscience, \\ Chiba University Center for Forensic \\ Mental Health, Chiba, Japan
}

Correspondence: Yakup Albayrak Namık Kemal University, Uygulama ve Arastirma Hastanesi, Tunca Caddesi, I00. Yil Mahallesi, Tekirdag, Turkey Tel +90505 6355434

Email dr.fuge@hotmail.com
Background: Brain-derived neurotrophic factor (BDNF) is a well-established neurotrophin that plays a role in the pathophysiology of numerous psychiatric disorders. Many studies have investigated the serum BDNF levels in patients with schizophrenia. However, there are restricted data in the literature that compare the serum BDNF levels in patients with deficit and nondeficit syndromes. In this study, we aimed to compare the serum BDNF levels between schizophrenic patients with deficit or nondeficit syndrome and healthy controls.

Methods: After fulfilling the inclusion and exclusion criteria, 58 patients with schizophrenia and 36 healthy controls were included in the study. The patients were grouped as deficit syndrome $(\mathrm{N}=23)$ and nondeficit syndrome $(\mathrm{N}=35)$ according to the Schedule for the Deficit Syndrome. Three groups were compared in terms of the sociodemographic and clinical variants and serum BDNF levels.

Results: The groups were similar in terms of age, sex, body mass index, and smoking status. The serum BDNF levels in patients with deficit syndrome were significantly lower than those in healthy controls. In contrast, the serum BDNF levels in patients with nondeficit syndrome were similar to those in healthy controls.

Conclusion: This study suggests that decreased BDNF levels may play a role in the pathophysiology of schizophrenic patients with deficit syndrome. Nonetheless, additional studies using a larger patient sample size are needed to investigate the serum BDNF levels in schizophrenic patients with deficit syndrome.

Keywords: biomarker, neurotrophin, psychosis

\section{Introduction}

Schizophrenia is a chronic, devastating disorder that is observed in approximately $1 \%$ of the population worldwide. The symptomatology of schizophrenia is heterogeneous, and there have been efforts to determine the subclasses of schizophrenia. ${ }^{1,2}$ Although there have been subtypes of schizophrenia used according to Diagnostic and Statistical Manual of Mental Disorders (DSM) Fourth Edition Text Revised, in DSM-V, the subtypes of schizophrenia have been removed because of their limited diagnostic stability, low reliability, and poor validity. ${ }^{3,4}$ However, subclassing a heterogeneous disorder, such as schizophrenia, can be considered to be imperious.

In 1988, Carpenter et $\mathrm{al}^{5}$ described deficit schizophrenia in a homogeneous subclass of patients with schizophrenia characterized by primary and continuous negative symptoms. They also considered and suggested that schizophrenia with deficit syndrome (DS) was a distinct illness in contrast to nondeficit schizophrenia (NDS). ${ }^{5-8}$ Since the definition of DS as a distinct entity compared with NDS has been recognized, this concept has been more plausible and more powerful. 
Brain-derived neurotrophic factor (BDNF) is first produced as a precursor protein, prepro-BDNF, in the endoplasmic reticulum. Following cleavage of the signal peptide, proBDNF is transported to the Golgi for sorting into either the constitutive or the regulated secretory vesicles. ProBDNF is converted to the mature BDNF by extracellular proteases, such as matrix metalloproteinase- 9 and plasmin. ${ }^{9-16}$ It has been well established that BDNF can freely cross the blood-brain barrier and that the measurements of blood BDNF levels can substantially reflect the situation of BDNF in the central nervous system. ${ }^{17}$ Although there have been inconsistencies in the studies that investigated the serum BDNF levels in patients with schizophrenia; the majority of the studies revealed reduced serum BDNF levels in chronic and medicated patients with schizophrenia. ${ }^{18-23}$ Additionally, research has reported marked decreases in the BDNF levels during first-episode schizophrenia and in drug-naïve patients with schizophrenia. ${ }^{24-28}$ Unlike these findings, several studies have reported increased and similar serum BDNF levels in patients with schizophrenia compared with healthy subjects. ${ }^{29-32}$ These confounding findings concerning the serum BDNF levels in patients with schizophrenia may be associated with the stage of illness, the duration of illness, sample sizes, and the heterogeneity of the illness. In a metaanalysis, the reduced serum BDNF levels were reported in medicated and drug-naïve patients with schizophrenia. Following a meta-regression, an association was reported between the serum BDNF levels and age; however, there was no relationship between the medication dosage and the serum BDNF levels in patients with schizophrenia. ${ }^{33}$

Limited numbers of studies have compared the serum BDNF levels between patients with DS schizophrenia, NDS, and healthy controls (HC). In the present study, we aimed to demonstrate whether there is a discrepancy between schizophrenic patients with DS and NDS and HC in terms of serum BDNF levels.

\section{Methods}

\section{Subjects}

This study was conducted in the Department of Psychiatry, Yenimahalle Education and Research Hospital, Ankara, Turkey between March 2014 and June 2014. The patients who were diagnosed with schizophrenia and who were followed by the outpatient clinic of Yenimahalle Education and Research Hospital participated in the study. The diagnosis of the patients was confirmed by a senior psychiatrist (ESA) using the Structured Clinical Interview for DSM-IV Axis I before their inclusion in the study. ${ }^{34,35}$ The inclusion criteria were as follows: diagnosis of schizophrenia; age between 18 and 60 years; being in the stable phase of schizophrenia; and willingness to participate in the study after a detailed explanation of the study. Schizophrenic patients can be considered to be in a stable phase of the disease if there has not been any deterioration in symptoms and if there has been no need to change the treatment during a determined time period. However, these time periods are not formally established. Several researchers have defined time periods according to their particular research methods. For example, according to Rocca et al schizophrenia can be considered to be in a stable phase if the patient has not had any increase in symptomatology during the last year and if their antipsychotic regimen was unchanged for the last 6 months. ${ }^{36}$ In another study, Mendrek et al defined stable phase as "no relapse within the last two months and no change in their antipsychotic treatment within the last month. ${ }^{37}$ In our research, we suggested the term of clinical stability according to Rocca et al. The exclusion criteria were as follows: having dementia or cognitive deterioration according to the Mini-Mental State Examination (score $<23$ ); having a history of alcohol or substance dependence, major head trauma, any recent or previous chronic illness, comorbid psychiatric disorder, or extrapyramidal symptoms due to medication; unwillingness to participate in the study; and being in an exacerbation phase of schizophrenia. After adhering to the inclusion and exclusion criteria, 58 patients were included in the study. All of the patients who were included in the study had received atypical antipsychotic treatment. Eleven patients were treated with clozapine, 12 patients were treated with risperidone, seven patients were treated with paliperidone, 12 patients were treated with olanzapine, ten patients were treated with quetiapine, and six patients were treated with a combination of atypical antipsychotics. The antipsychotic doses were converted to international chlorpromazine doses to compare patient groups. ${ }^{38}$ Additionally, 36 age/sex matched healthy individuals who were selected from the hospital staff were included in the study. Detailed psychiatric and medical family histories were received from the HC group, and none of them had a family history of schizophrenia. The Turgut Özal University Ethics Committee approved the present study. All of the patients reported that they understood the written informed consent and approved it. Furthermore, a clear explanation was given to the families of patients who were included in the study; they also accepted our study protocol and design of the present study, and they approved the informed consent. All of the HC agreed to be included in the present study, and all of them provided their informed 
consent. All of the patients and healthy individuals were assessed in terms of weight and height, and the body mass index (BMI) was calculated for each participant.

\section{Psychopathological assessment in patients Instruments}

Structured Clinical Interview for DSM-IV

Axis I (SCID-I)

SCID-I is a semistuctured tool for diagnosing the disorders that are classified in DSM-IV Axis I. This structured diagnostic tool is applied by a psychiatrist or anyone who is trained as a mental health professional. First et al developed this instrument, which has been reported to be reliable and validated in the Turkish language. ${ }^{34,35}$

\section{Schedule for the Deficit Syndrome}

The patients were subtyped with or without deficit by applying the Schedule for the Deficit Syndrome, ${ }^{6}$ a semistructured interviewing tool that describes the DS with at least two of six enduring negative symptoms of schizophrenia, including restricted affect, diminished emotional range, speech poverty, diminished interests, diminished sense of aim, and diminished social drive of at least moderate severity. The present negative symptoms must last for a minimum of 12 months, even during periods of clinical stability. Confounding factors, such as anxiety, medication effect, positive symptoms, mental retardation, and depression, must be excluded. Family members and associated clinicians also confirmed the deficit state. This schedule has been reported to be validated and reliable in the Turkish language. ${ }^{39}$

\section{Scale for the Assessment of Negative Symptoms} (SANS)

This scale was produced for scoring the clinical ratings of negative symptoms in patients with schizophrenia. Affective blunting, alogia (impoverished thinking), avolition/apathy, anhedonia/asociality, and disturbance of attention are the negative symptoms. The scorings are applied using a sixpoint scale $(0=$ not at all, to $5=$ severe $)$. SANS was produced by Andreasen. ${ }^{40}$ The Turkish version was validated and was reported to be reliable in $1991 .^{41}$

\section{Scale for the Assessment of Positive Symptoms (SAPS)}

This scale was created to evaluate and score the positive symptoms that are frequently observed in patients with schizophrenia. These positive symptoms consist of hallucinations, delusions, bizarre behavior, and positive formal thought disorder. SAPS was produced by Andreasen. ${ }^{42}$ The Turkish version was reported to be reliable by Erkoç et al. ${ }^{43}$

\section{Brief Psychiatric Rating Scale (BPRS)}

This rating scale was created for measuring psychiatric symptoms, such as negative symptoms, positive symptoms, disorganized behavior and speech, anxiety, and depression. The scores range from 1 to 7 , and there are two versions with 18 to 24 symptoms. BPRS was created by Overall and Gorham, and its Turkish translation is available and is widely used in clinical practice. ${ }^{44}$

\section{Mini Mental State Examination}

This structured clinician-rated interview aims to evaluate the presence and the level of cognitive impairment. The evaluation consists of nine items: memory; orientation; attention; verbal fluency; nominal aphasia; receptive aphasia plus receptive apraxia; alexia; agraphia; and constructional apraxia. Folstein et al developed this scale, and its Turkish translation is available. ${ }^{45}$

\section{Biochemical procedures}

The blood samples were collected at 8 am, after an overnight fast of at least 12 hours. The serum samples were extracted from the whole blood samples by centrifugation at 2,000 rpm for 15 minutes and were immediately frozen. The serum samples were extracted using a refrigerated centrifuge at room temperature. All of the serum samples were preserved at $-80^{\circ} \mathrm{C}$ until the analysis could be performed. Using a double-antibody sandwich enzyme-linked immunosorbent assay (ELISA) technique, the BDNF serum levels were determined using a commercial kit (Sunred Biological Technology, Shanghai, People's Republic of China). The samples were processed as recommended by the kit and run in random for the ELISA. The standard curve ranged from $0.1 \mathrm{ng} / \mathrm{mL}$ to $10 \mathrm{ng} / \mathrm{mL}$ of BDNF. The standard curve showed a direct relationship between the optical density and the BDNF concentration. Two determinations of the BDNF levels were performed for each sample, and the result is reported as the mean of both determinations. The intra-assay coefficient of variation was found to be $<10 \%$. The analytic sensitivity of BDNF ELISA was $0.08 \mathrm{ng} / \mathrm{mL}$. Additionally, all of the participants were evaluated in terms of BMI, which can affect the serum BDNF levels.

\section{Statistical methods}

The Statistical Package for the Social Sciences, PC version 17.0 (SPSS Inc., Chicago, IL, USA), was used for the 
data analysis. A confidence interval of $95 \%$ and a two-tailed $P<0.05$ were accepted to be statistically significant for all of the analyses. The variables were tested for homogeneity of variance using the Levene test and for normality of distribution using the Kolmogorov-Smirnov test. The differences between age and BMI were tested using a series of one-way analyses of variance; if a difference was found between groups, Tukey's honest significant difference was applied to determine the difference between groups in detail. The categorical variables, such as sex and smoking status, were assessed using a $\chi^{2}$ test. The Student's $t$-test was used to evaluate the differences between both patient groups in terms of the scores on the SANS, SAPS, and BPRS, and the duration of illness. The numerical variants are expressed as the mean \pm standard deviation values between the patient groups. The associations between parametric variables were assessed using Pearson's correlation coefficients in all participants and according to each group. Because the serum BDNF levels might be influenced by age and BMI, ${ }^{46,47}$ a general linear model was used to compare the serum BDNF levels between the groups (age and BMI covariates).

\section{Results}

Twenty-three patients were subtyped as DS and 35 patients were classified as NDS according to the Schedule for Deficit Syndrome. In our study, a continuous response variable for $\mathrm{HC}$ and schizophrenia subjects required 0.62 controls per schizophrenia subject. In a previous study, the responses within each subject group were normally distributed; the means for HC and schizophrenic subjects were $49.3 \mathrm{ng} / \mathrm{mL}$ and $40.8 \mathrm{ng} / \mathrm{mL}$, respectively, and the standard deviations for $\mathrm{HC}$ and schizophrenic subjects were $14.2 \mathrm{ng} / \mathrm{mL}$ and $8.2 \mathrm{ng} / \mathrm{mL}$, respectively. ${ }^{48} \mathrm{We}$ assessed 58 schizophrenic subjects and 36 controls subjects to be able to reject the null hypothesis that the population means of the experimental and control groups are equal with a probability (power) of 0.9 . The Type I error probability associated with this test of the null hypothesis was 0.5 .

The mean ages were found to not significantly differ between the groups $(F=1.46, P=0.23)$. The groups were similar in terms of sex, BMI, and smoking status $\left(\chi^{2}=2.07\right.$, $P=0.35 ; F=1.70, P=0.18 ; \chi^{2}=2.46, P=0.29$, respectively). The mean BPRS score in the DS group (27.18 \pm 11.19$)$ was similar to that in the NDS group $(21.26 \pm 12.81)(t=-1.81, P=0.07)$. The mean SANS score in the DS group (51.08 \pm 19.29$)$ was found to be significantly higher than the score in the NDS group (22.92 \pm 12.37$)(t=-5.19, P<0.001)$. The mean SAPS scores, the mean chlorpromazine equivalent dose, and the duration of illness were similar between the groups $(t=-1.01$, $P=0.26 ; t=0.90, P=0.37 ; t=-1.81, P=0.08$, respectively) (Table 1).

As described in the "Methods" section, the general linear model was used for comparing the serum BDNF levels between the groups. The dependent variable was the serum BDNF level, and age and BMI were included in the model as covariants. The serum BDNF levels in the NDS, DS, and $\mathrm{HC}$ groups were $1.31 \pm 0.87 \mathrm{ng} / \mathrm{dL}, 1.09 \pm 0.94 \mathrm{ng} / \mathrm{dL}$, and $1.43 \pm 0.81 \mathrm{ng} / \mathrm{dL}$, respectively, with a significant difference between the groups $(F[2,89]=5.44 ; P=0.006)$. A pairwise comparison revealed that the serum BDNF level was significantly lower in the DS group compared with the $\mathrm{HC}$ group ( $P=0.004)$. However, we failed to find any significant

Table I Sociodemographic and clinical characteristics of participants

\begin{tabular}{|c|c|c|c|c|}
\hline & NDS $(\mathbf{N}=35)$ & DS $(\mathbf{N}=23)$ & $\mathrm{HC}(\mathrm{N}=36)$ & Statistics \\
\hline Age (years) & $36.37 \pm 6.91$ & $36.34 \pm 6.04$ & $33.36 \pm 10.37$ & $F=1.46, P=0.23$ \\
\hline \multicolumn{5}{|l|}{ Sex } \\
\hline Female & $20(57.1 \%)$ & 9 (39.1\%) & $20(55.6 \%)$ & \multirow{2}{*}{$\chi^{2}=2.07, P=0.35$} \\
\hline Male & 15 (42.9\%) & 14 (60.9\%) & $16(44.4 \%)$ & \\
\hline \multicolumn{5}{|l|}{ Smoking status } \\
\hline Yes & $18(51.6 \%)$ & $9(39.1 \%)$ & $12(33.6 \%)$ & \multirow[t]{2}{*}{$\chi^{2}=2.46, P=0.29$} \\
\hline No & $17(48.6 \%)$ & 14 (60.9\%) & $24(66.6 \%)$ & \\
\hline BMI & $25.53 \pm 4.78$ & $25.00 \pm 4.05$ & $23.91 \pm 3.70$ & $F=1.70, P=0.35$ \\
\hline SANS & $22.92 \pm 12.37$ & $51.08 \pm 19.29$ & - & $t=-5.19, \mathbf{P}<\mathbf{0 . 0 0 1}$ \\
\hline SAPS & $26.08 \pm \mid 5.31$ & $24.55 \pm 9.71$ & - & $t=-1.01, P=0.26$ \\
\hline BPRS & $21.26 \pm|2.8|$ & $27.18 \pm 11.19$ & - & $t=-1.81, P=0.07$ \\
\hline Duration of illness (years) & $|4.7| \pm 6.67$ & $17.82 \pm 5.98$ & - & $t=-1.81, P=0.08$ \\
\hline Chlorpromazine-equivalent dose & $538.63 \pm 357.54$ & $411.36 \pm 321.50$ & - & $t=0.90, P=0.37$ \\
\hline
\end{tabular}

Note: Significant $P$-values shown in bold.

Abbreviations: BMI, body mass index; BPRS, Brief Psychiatric Rating Scale; DS, deficit schizophrenia; HC, healthy controls; NDS, nondeficit schizophrenia; SANS, Scale for the Assessment of Negative Symptoms; SAPS, Scale for the Assessment of Positive Symptoms. 
Table 2 Comparison of serum BDNF levels between groups

\begin{tabular}{lllll}
\hline & $\begin{array}{l}\text { NDS } \\
(\mathbf{N}=\mathbf{3 5})\end{array}$ & $\begin{array}{l}\text { DS } \\
\mathbf{( N = 2 3 )}\end{array}$ & $\begin{array}{l}\text { HC } \\
\mathbf{( N = 3 6 )}\end{array}$ & Statistic \\
\hline $\operatorname{BDNF}(\mathrm{ng} / \mathrm{mL})$ & $\mathrm{I} .3 \mathrm{I} \pm 0.87$ & $\mathrm{I} .09 \pm 0.94$ & $1.43 \pm 0.8 \mathrm{I}$ & $F(2,89)=5.44 ; P=0.006$ \\
\hline
\end{tabular}

Note: Age and body mass index were included to model as covariants.

Abbreviations: BDNF, brain-derived neurotrophic factor; DS, deficit schizophrenia; $\mathrm{HC}$, healthy controls; NDS, nondeficit schizophrenia.

differences between the NDS and DS groups and the $\mathrm{HC}$ and NDS groups ( $P=0.19$ and $P=0.50$, respectively) (Table 2). The dot plot was produced for demonstrating the distribution of the serum BDNF level for each group (Figure 1).

We first assessed the coefficients between the serum BDNF levels and age; BMI; BPRS, SANS, and SAPS scores; the duration of illness; and chlorpromazine equivalent dose in all of the groups. The serum BDNF levels were found to have a significant negative correlation with the SANS score $(r=-0.238 ; P=0.03)$. There was no significant correlation between the serum BDNF levels and BMI, age, BPRS score, SAPS score, the duration of illness, and chlorpromazine equivalent dose $(r=-0.011 ; P=0.91 ; r=-0.024 ; P=0.98$; $r=-0.134 ; P=0.31 ; r=-0.145 ; P=0.27 ; r=-0.143 ; P=0.38$; $r=-0.164 ; P=0.36$, respectively) (Table 3). The Pearson's correlation analysis was conducted for each group separately to investigate the association between the serum BDNF levels and age; BMI; BPRS, SANS, and SAPS scores; the duration of illness; and chlorpromazine equivalent dose. There was no significant correlation between the parameters in the NDS, DS, and HC groups (Table 4).

\section{Discussion}

A major finding of this study is the reduced serum BDNF levels in the DS group compared with the HC group. However, we failed to find any significant differences between the NDS and DS groups and between the NDS and HC groups in terms of the serum BDNF levels.

The serum BDNF levels are widely measured in numerous psychiatric disorders. The use of BDNF is best known and established in synaptic plasticity, and BDNF plays a potential role in the disease etiology and in the treatment of many psychiatric disorders. ${ }^{49,50}$ During development, BDNF plays an important role in maintaining proper axonal growth. ${ }^{51} \mathrm{BDNF}$ is also regarded to be essential for the
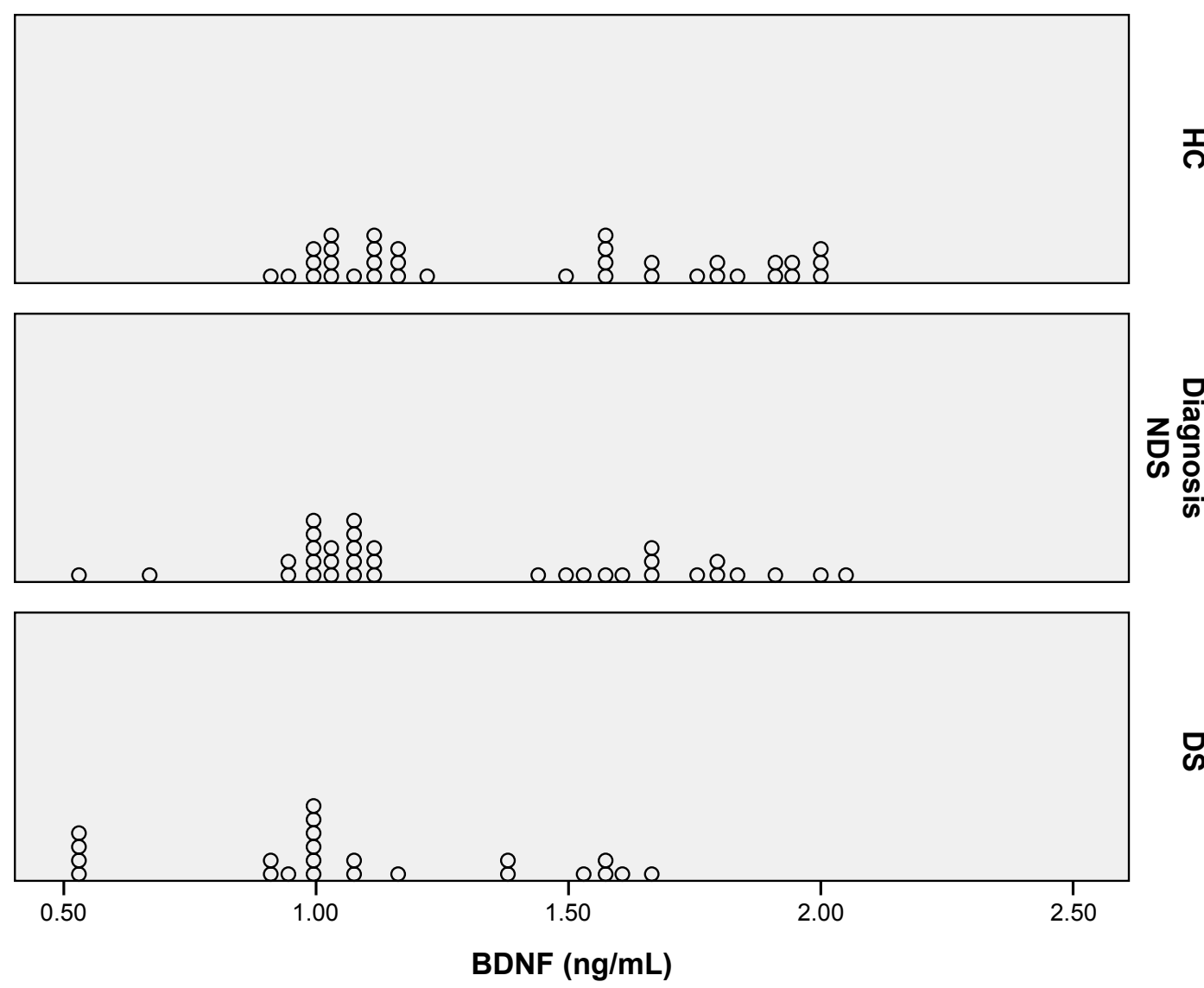

ஜ

Figure I Dot plot of serum BDNF level according to groups.

Abbreviations: BDNF, brain-derived neurotrophic factor; DS, deficit schizophrenia; HC, healthy controls; NDS, nondeficit schizophrenia. 
Table 3 Correlation coefficients between scores of BDNF and age, BMI, SANS, SAPS, BPRS, duration of illness, and mean antipsychotic dose in participants

\begin{tabular}{llllllll}
\hline & Age & BMI & BPRS & SANS & SAPS & $\begin{array}{l}\text { Duration } \\
\text { of illness }\end{array}$ & $\begin{array}{l}\text { Mean antipsychotic } \\
\text { dose** }\end{array}$ \\
\hline BDNF & -0.024 & -0.011 & -0.134 & $-0.238^{*}$ & -0.145 & -0.143 & -0.164 \\
\hline
\end{tabular}

Notes: $* P=0.03$. $* *$ Chlorpromazine-equivalent dose.

Abbreviations: BDNF, brain-derived neurotrophic factor; BMI, body mass index; BPRS, Brief Psychiatric Rating Scale; SANS, Scale for the Assessment of Negative Symptoms; SAPS, Scale for the Assessment of Positive Symptoms.

development and the survival of dopaminergic, serotonergic, GABAergic, and cholinergic neurons. ${ }^{52}$ The BDNF signaling action develops in a short time, eg, within seconds, and can support long-term potentiation, which enhances the synaptic strengths between neurons. ${ }^{53}$

As mentioned in the "Introduction", BDNF seems to play a role in the etiology of schizophrenia. Although the results of studies that investigated serum BDNF levels are inconsistent, a meta-analysis by Green et al revealed that decreased serum BDNF levels were associated with schizophrenia. ${ }^{33}$ However, limited numbers of studies have compared serum BDNF levels between NDS and DS. Valiente-Gómez et al recently reported similar serum BDNF levels between NDS and DS. In this study, patients with schizophrenia were reported to have decreased serum BDNF levels compared with those observed in HC. After this comparison, they aimed to subclass the patients as deficit patients and nondeficit patients, and they revealed similar serum BDNF levels between the patient groups. To the best of our knowledge, this study was the first and the only study that compared serum BDNF levels between patients with DS and NDS..$^{48}$ An association between serum BDNF levels and both cognitive impairment and negative symptoms of schizophrenia has been reported. ${ }^{54-56}$ Recently, Niitsu et al investigated the mature BDNF levels in patients with schizophrenia. They reported that the serum mature BDNF levels were similar between patients with schizophrenia and $\mathrm{HC}$ and that there was a positive correlation between serum mature BDNF levels and negative symptoms. They concluded that the mature BDNF might not be a good candidate as a biomarker in schizophrenia. ${ }^{57}$ However, none of these studies classified the patients as DS and NDS. In our study, we found a significant negative correlation between serum BDNF levels and SANS scores while assessing the correlation coefficient in the entire group of participants. However, we failed to demonstrate this correlation when the correlation analysis was separately performed for each group. Thus, we suggest that there might be a negative correlation between serum BDNF levels and SANS scores; however, additional studies are needed to demonstrate and replicate this finding.

As previously mentioned, the inconsistent findings of studies that evaluated serum BDNF levels might be attributed to the heterogeneous nature of the disorder. There has been only one previous study that aimed to demonstrate the comparison of serum BDNF levels in patients with DS, NDS, and HC. ${ }^{58}$ Actually, the findings of our study demonstrate two aspects. First, we argue that our study is consistent with the findings of the studies that reported similar serum BDNF levels between patients with schizophrenia and healthy subjects. ${ }^{31,32,54}$ Second, regarding the decreased serum BDNF levels in DS patients, serum BDNF level might be a good candidate indicator for a specific subtype of schizophrenia, such as DS. Since the introduction of the term deficit schizophrenia in the literature, several research articles have investigated the clinical, biological, and sociodemographic aspects of deficit schizophrenia. ${ }^{58}$ Thus, the present study supports the concept that DS schizophrenia is a different disease entity.

BDNF levels have been most frequently investigated in the context of major depressive disorder (MDD); many clinical studies have shown consistently that BDNF levels are decreased in patients with MDD. ${ }^{59,60}$ Although there are several similarities between deficit schizophrenia and MDD in terms of signs and symptoms, the criteria for the

Table 4 Correlation coefficients between scores of BDNF and age, BMI, SANS, SAPS, BPRS, duration of illness, and mean antipsychotic dose in NDS, DS, and HC groups

\begin{tabular}{lllllllll}
\hline & & Age & BMI & BPRS & SANS & SAPS & $\begin{array}{l}\text { Duration } \\
\text { of illness }\end{array}$ & $\begin{array}{l}\text { Mean antipsychotic } \\
\text { dose* }\end{array}$ \\
\hline NDS & BDNF & -0.068 & -0.004 & -0.022 & -0.018 & 0.050 & -0.208 & 0.166 \\
DS & BDNF & 0.088 & -0.129 & -0.180 & -0.381 & -0.219 & 0.150 & 0.049 \\
HC & BDNF & 0.052 & -0.157 & - & - & - & - & - \\
\hline
\end{tabular}

Note: *Chlorpromazine-equivalent dose.

Abbreviations: BDNF, brain-derived neurotrophic factor; BMI, body mass index; BPRS, Brief Psychiatric Rating Scale; DS, deficit schizophrenia; HC, healthy controls; NDS, nondeficit schizophrenia; SANS, Scale for the Assessment of Negative Symptoms; SAPS, Scale for the Assessment of Positive Symptoms. 
DS stipulate that the symptoms must be primary, not secondary, to factors such as anxiety, depression, drug effect, or mental retardation. ${ }^{58}$ Therefore, decreases in the BDNF levels in the DS group cannot be interpreted as a result of affective symptomatology. Given that DS is not an affective disorder, BDNF levels may be associated with other common aspects of these two discrete entities. Additional research is warranted to investigate and determine these aspects.

The present study has several limitations. First, the numbers of participants might be considered to be a limitation. However, this limitation is due to the strict inclusion and exclusion criteria for participating in the study. BDNF is first produced as a precursor that is known as proBDNF. Although ELISA kits can measure the total levels of BDNF (mature BDNF and proBDNF), they are unable to distinguish between proBDNF and mature BDNF. ${ }^{9,13,16,61}$ Additional studies on the measurements of both mature BDNF and proBDNF will be of great value to evaluating schizophrenic patients with DS and NDS. In addition, serum BDNF levels might be influenced by the patient's menstrual cycle. ${ }^{62} \mathrm{We}$ could not assess the menstrual cycle of female participants in the present study, which was another limitation.

\section{Conclusion}

To the best of our knowledge, the present study is the first to demonstrate decreased serum BDNF levels in patients with DS. We hypothesize that our finding is important in supporting the concept that considers DS as a different clinical entity of schizophrenia. This study highlights the worse prognosis of DS and provides a biological explanation. However, additional studies are warranted to investigate the role of BDNF in DS.

\section{Disclosure}

The authors report no conflicts of interest in this work.

\section{References}

1. Eaton WW, Martins SS, Nestadt G, Bienvenu OJ, Clarke D, Alexandre P. The burden of mental disorders. Epidemiol Rev. 2008;30:1-14.

2. Tandon R, Nasrallah HA, Keshavan MS. Schizophrenia, "just the facts" 4. Clinical features and conceptualization. Schizophr Res. 2009;110(1-3):1-23.

3. American Psychiatric Association. Diagnostic and Statistical Manual of Mental Disorders. 4th ed. Washington, DC: American Psychiatric Association; 2000.

4. American Psychiatric Association. Diagnostic and Statistical Manual of Mental Disorders. 5th ed. Washington, DC: American Psychiatric Association; 2013.

5. Carpenter WT Jr, Heinrichs D, Wagman AM. Deficit and nondeficit forms of schizophrenia: the concept. Am J Psychiatry. 1988;145:578-583.

6. Kirkpatrick B, Buchanan RW, McKenny PD, Alphs LD, Carpenter WT Jr. The Schedule for the Deficit Syndrome: an instrument for research in schizophrenia. Psychiatry Res. 1989;30:119-123.
7. Carpenter WT Jr, Arango C, Buchanan RW, Kirkpatrick B. Deficit psychopathology and a paradigm shift in schizophrenia research. Biol Psychiatry. 1999;46:352-360.

8. Kirkpatrick B, Buchanan RW, Ross DE, Carpenter WT Jr. A separate disease within the syndrome of schizophrenia. Arch Gen Psychiatry. 2001;58:165-171.

9. Hashimoto K. Brain-derived neurotrophic factor (BDNF) and its precursor proBDNF as diagnostic biomarkers for major depressive disorder and bipolar disorder. Eur Arch Psychiatry Clin Neurosci. Epub 2014 Nov 2.

10. Lu B. Pro-region of neurotrophins: role in synaptic modulation. Neuron. 2003;39:735-738.

11. Lu B, Pang PT, Woo NH. The yin and yang of neurotrophin action. Nat Rev Neurosci. 2005;6:603-614.

12. Hashimoto K. BDNF variant linked to anxiety-related behaviors. Bioessays. 2007;29:116-119.

13. Hashimoto K. Brain-derived neurotrophic factor as a biomarker for mood disorders: a historical overview and future directions. Psychiatry Clin Neurosci. 2010;64:341-357.

14. Hwang JJ, Park MH, Choi SY, Koh JY. Activation of the Trk signaling pathway by extracellular zinc. Role of metalloproteinases. J Biol Chem. 2005;280:11995-12001.

15. Ethell IM, Ethel DW. Matrix metalloproteinases in brain development and remodeling: synaptic functions and targets. $J$ Neurosci Res. 2007;85:2813-2823.

16. Yoshida T, Ishikawa M, Iyo M, Hashimoto K. Serum levels of mature brain-derived neurotrophic factor (BDNF) and its precursor proBDNF in healthy subjects. The Open Clinical Chemical Journal. 2012;5:7-12.

17. Pan W, Bank WA, Fasold MB, Bluth J, Kastin AJ. Transport of brainderived neurotrophic factor across the blood-brain barrier. Neuropharmacology. 1998;37(12):1553-1561.

18. Grillo RW, Ottoni GL, Leke R, Souza DO, Portela LV, Lara DR. Reduced serum BDNF levels in schizophrenic patients on clozapine or typical antipsychotics. $J$ Psychiatr Res. 2007;41:31-35.

19. Toyooka K, Asama K, Watanabe Y, et al. Decreased levels of brainderived neurotrophic factor in serum of chronic schizophrenic patients. Psychiatry Res. 2002;110(3):249-257.

20. Xiu MH, Hui L, Dang YF, et al. Decreased serum BDNF levels in chronic institutionalized schizophrenia on long-term treatment with typical and atypical antipsychotics. Prog Neuropsychopharmacol Biol Psychiatry. 2009;33(8):1508-1512.

21. Tan YL, Zhou DF, Zhang XY. Decreased plasma brain-derived neurotrophic factor in schizophrenic patients with tardive dyskinesia: association with dyskinetic movements. Schizophr Res. 2005; 74:263-270

22. Zhang XY, Tan YL, Zhou DF, et al. Serum BDNF levels and weight gain in schizophrenic patients on long-term treatment with antipsychotics. J Psychiatr Res. 2007;41(12):997-1004.

23. Ikeda Y, Yahata N, Ito I, et al. Low serum levels of brain-derived neurotrophic factor and epidermal growth factor in patients with chronic schizophrenia. Schizophr Res. 2008;101(1-3):58-66.

24. Buckley PF, Pillai A, Evans D, Stirewalt E, Mahadik S. Brain derived neurotropic factor in first-episode psychosis. Schizophr Res. 2007;91(1-3):1-5.

25. Palomino A, Vallejo-Illarramendi A, González-Pinto A, et al. Decreased levels of plasma BDNF in first-episode schizophrenia and bipolar disorder patients. Schizophr. Res. 2006;86(1-3):321-322.

26. Pirildar S, Gönül AS, Taneli F, Akdeniz F. Low serum levels of brainderived neurotrophic factor in patients with schizophrenia do not elevate after antipsychotic treatment. Prog Neuropsychopharmacol Biol Psychiatry. 2004;28:709-713.

27. Rizos EN, Papadopoulou A, Laskos E, et al. Reduced serum BDNF levels in patients with chronic schizophrenic disorder in relapse, who were treated with typical or atypical antipsychotics. World J Biol Psychiatry. 2010;11(2 Pt 2):251-255.

28. Chen da C, Wang J, Wang B, et al. Decreased levels of serum brainderived neurotrophic factor in drug-naïve first-episode schizophrenia: relationship to clinical phenotypes. Psychopharmacology (Berl). 2009;207(3):375-380 
29. Gama CS, Andreazza AC, Kunz M, Berk M, Belmonte-de-Abreu PS, Kapczinski F. Serum levels of brain-derived neurotrophic factor in patients with schizophrenia and bipolar disorder. Neurosci Lett. 2007;420(1):45-48.

30. Reis HJ, Nicolato R, Barbosa IG, Teixeira do Prado PH, Romano-Silva MA, Teixeira AL. Increased serum levels of brain-derived neurotrophic factor in chronic institutionalized patients with schizophrenia. Neurosci Lett. 2008;439(2):157-159.

31. Huang TL, Lee CT. Associations between serum brain-derived neurotrophic factor levels and clinical phenotypes in schizophrenia patients. J Psychiatr Res. 2006;40(7):664-668.

32. Shimizu E, Hashimoto K, Watanabe H, et al. Serum brain-derived neurotrophic factor (BDNF) levels in schizophrenia are indistinguishable from controls. Neurosci Lett. 2003;351(2):111-114.

33. Green MJ, Matheson SL, Shepherd A, Weickert CS, Carr VJ. Brainderived neurotrophic factor levels in schizophrenia: a systematic review with meta-analysis. Mol Psychiatry. 2011;16(9):960-972.

34. Corapcioglu A, Aydemir O, Yildiz M. Structured Clinical Interview for DSM-IV (SCID-IV), Turkish Version (Turkish). Ankara, Turkey: Hekimler Yayin Birligi; 1999.

35. First MB, Spitzer RL, Gibbon M, Williams JBW. Structured Clinical Interview for DSM-IV Axis I Disorders, Clinician Version (SCID-CV). Washington, DC: American Psychiatric Press, Inc.; 1996.

36. Rocca P, Pulvirenti L, Montemagni C, Rasetti R, Rocca G, Bogetto F. Basic symptoms in stable schizophrenia: Relations with functioning and quality of life. Clin Neuropsychiatry. 2010;7(3):100-110.

37. Mendrek A, Bourque J, Dubé A, Lakis N, Champagne J. Emotion processing in women with schizophrenia is menstrual cycle phase and affective valance dependent: an fMRI study. ISRN Psychiatry. 2012;2012:656274.

38. Woods SW. Chlorpromazine equivalent doses for the newer atypical antipsychotics. J Clin Psychiatry. 2003;64:663-667.

39. Citak S, Oral ET, Aker AT, Senocak M. [Reliability and validity of the schedule for deficit syndrome in schizophrenia]. Turk Psikiyatri Derg. 2006;17(2):115-127. Turkish.

40. Andreasen NC. Scale for the Assessment of Negative Symptoms: SANS. Iowa City, IA: College of Medicine, University of Iowa. 1984.

41. Erkoç S, Arkonaç O, Ataklı C, Ozmen E. Negatif semptomları değerlendirme ölçeğinin güvenirliği ve geçerliliği. [The reliability and validity of scale for the assessment of negative symptoms.] Düşünen Adam. 1991;4:16-19. Turkish.

42. Andreasen NC. Scale for the Assessment of Positive Symptoms (SAPS). Iowa City, IA: College of Medicine, University of Iowa. 1984.

43. Erkoç S, Arkonaç O, Atakl 1 C, Ozmen E. Pozitif semptomları değerlendirme ölçeğinin güvenirlirliği ve geçerliliği. [The reliability and validity of scale for the assessment of positive symptoms.] Düşünen Adam. 1991;4:20-24. Turkish.

44. Overall JE, Gorham DR. The Brief Psychiatric Rating Scale. Psychol Rep. 1962;10:799-812.

45. Folstein M, Folstein SE, McHugh PR. "Mini-Mental State". A Practical Method for Grading the Cognitive State of Patients for the Clinician. J Psychiatr Res. 1975;12(3):189-198.
46. Lommatzsch M, Zingler D, Schuhbaeck K, et al. The impact of age, weight and gender on BDNF levels in human platelets and plasma. Neurobiol Aging. 2005;26:115-123.

47. Pluchino N, Russo M, Santoro AN, Litta P, Cela V, Genazzani AR. Steroid hormones and BDNF. Neuroscience. 2013;239:271-279.

48. Valiente-Gómez A, Amann BL, Mármol F, et al. Comparison of serum BDNF levels in deficit and nondeficit chronic schizophrenia and healthy controls. Psychiatry Res. 2014;220(1-2):197-200.

49. Lohof AM, Ip NY, Poo MM. Potentiation of developing neuromuscular synapses by the neurotrophins NT-3 and BDNF. Nature. 1993;363:350-353.

50. Kossel AH, Cambridge SB, Wagner U, Bonhoeffer T. A caged Ab reveals an immediate/instructive effect of BDNF during hippocampal synaptic potentiation. Proc Natl Acad Sci U S A. 2001;98:14702-14707.

51. Yoshii A, Constantine-Paton M. Postsynaptic BDNF-TrkB signaling in synapse maturation, plasticity, and disease. Dev Neurobiol. 2010;70:304-322.

52. Pillai A. Brain-derived neurotropic factor/TrkB signaling in the pathogenesis and novel pharmacotherapy of schizophrenia. Neurosignals. 2008;16:183-193.

53. Nagappan G, Lu B. Activity-dependent modulation of the BDNF receptor TrkB: mechanisms and implications. Trends Neurosci. 2005;28:464-471.

54. Vinogradov S, Fisher M, Holland C, Shelly W, Wolkowitz O, Mellon SH. Is serum brain-derived neurotrophic factor a biomarker for cognitive enhancement in schizophrenia? Biol Psychiatry. 2009;66:549-553.

55. Yang YQ, Sun S, Yu YQ, et al. Decreased serum brain-derived neurotrophic factor levels in schizophrenic patients with tardive dyskinesia. Neurosci Lett. 2011;502(1):37-40.

56. Zhang XY, Liang J, Chen da C, et al. Low BDNF is associated with cognitive impairment in chronic patients with schizophrenia. Psychopharmacology (Berl). 2012;222(2):277-284.

57. Niitsu $T$, Ishima $T$, Yoshida $T$, et al. A positive correlation between serum levels of mature brain-derived neurotrophic factor and negative symptoms in schizophrenia. Psychiatry Res. 2014;215(2):268-273.

58. Galderisi S, Maj M. Deficit schizophrenia: an overview of clinical, biological and treatment aspects. Eur Psychiatry. 2009;24(8):493-500.

59. Sen S, Duman R, Sanacora G. Serum brain-derived neurotrophic factor, depression, and antidepressant medications: meta-analyses and implications. Biol Psychiatry. 2008;64(6):527-532.

60. Bocchio-Chiavetto L, Bagnardi V, Zanardini R, et al. Serum and plasma BDNF levels in major depression: a replication study and meta-analyses. World J Biol Psychiatry. 2010;11(6):763-773.

61. Hashimoto K. Sigma-1 receptor chaperone and brain-derived neurotrophic factor: emerging links between cardiovascular disease and depression. Prog Neurobiol. 2013;100:15-29.

62. Cubeddu A, Bucci F, Giannini A, et al. Brain-derived neurotrophic factor plasma variation during the different phases of the menstrual cycle in women with premenstrual syndrome. Psychoneuroendocrinology. 2011;36(4):523-530.
Neuropsychiatric Disease and Treatment

\section{Publish your work in this journal}

Neuropsychiatric Disease and Treatment is an international, peerreviewed journal of clinical therapeutics and pharmacology focusing on concise rapid reporting of clinical or pre-clinical studies on a range of neuropsychiatric and neurological disorders. This journal is indexed on PubMed Central, the 'PsycINFO' database and CAS,

\section{Dovepress}

and is the official journal of The International Neuropsychiatric Association (INA). The manuscript management system is completely online and includes a very quick and fair peer-review system, which is all easy to use. Visit http://www.dovepress.com/testimonials.php to read real quotes from published authors. 